\title{
METHODS OF DISCRETIZATION OBJECTS CONTINUUM IMPLEMENTED IN FEM PREPROCESSORS
}

\author{
Sylwester Korga' ${ }^{1}$ Anna Makarewicz' ${ }^{1}$ Klaudiusz Lenik ${ }^{1}$ \\ 1 Fundamentals of Technology Faculty, Lublin University of Technlogy, Nadbystrzycka Str. 38, 20-618 Lublin, \\ Poland, e-mail: s.korga@pollub.pl
}

Received: 2015.10.11

Accepted: 2015.11.14

Published: 2015.12.04

\begin{abstract}
Finite Element Method (FEM) called Finite Element Analysis is a tool for computeraided engineering and analysis. It is used to solve problems related to changes in the geometry of the structure as a result of external factors. FEM is used to model engineering processes where real objects are converted to discrete models. Finite Element Method uses a method of obtaining approximate solutions by approximation of partial differential equations. The process of testing and mathematical computation model is described by the equations function of the position and time for the nodes. The development of individual models and their groups and definitions of boundary conditions are carried out using computer programs for FEM.
\end{abstract}

Keywords: discretization, Finite Element Method, models.

\section{INTRODUCTION}

Finite Element Method (FEM) is a widely used tool for computer-aided engineering calculations and analysis. FEM is treated as an indirect method between empirical and rational study. This method is understood as a method of research of a theoretical cognition. The physical processes and manufacturing are tested for using the experience with the use of mathematical methods and advanced computer techniques. Today, FEM is one of the basic methods used in the work of engineers, designers and technologists. It allows to analyze the state of stress and deformation bands of the examined model. FEM is used since the 1960's for calculations and computer simulations of phenomena engineering. Currently, FEM is used to calculate and simulate phenomena occurring in manufacturing processes $[1,2]$. Defining processes, the impact of the environment on models of research in computer programs, i.e. Deform 3D, Abaqus, Ansys, Adina is difficult as there are dynamic changes phenomena process. Parameters that are changed include: change of contact pressures, changing the actual area of contact, speed change tools and materials, variability of plastic deformation, etc. In many analyzes of computer material properties are approximate and assume the characteristics of linear or bilinear. Determining the conditions of material is based on laboratory experiments and the intuition of persons performing numerical analysis. These conditions affect the final result. Therefore, before FEM analysis you need to choose the correct boundary conditions. Despite these difficulties, the authors have attempted to define the conditions discretization in the process of shaping materials using computer calculation methods $[3,4,5]$.

\section{METHODS OF DISCRETIZATION OF CONTINUOUS OBJECTS IN THE FIELD OF FEM}

In the field of FEM solver calculation process depends on the amount and type of finite elements and their suitability for the tested models. Discretization process consists in dividing the continuum body called the real object, e.g. simple geometric solids. Simple blocks include nodes 
and interpolation functions (functions shape) that are used to describe the size distribution analyzed in its interior and on its sides.

Depending on the type of finite element nodes may be located in the vertices or the sides and in the interior. The finite elements of the linear type nodes are only the vertices. Discretization processes can be considered as:

- regular - where the grid discretization is characterized by a high degree of homogeneity and is adapted to the geometry of the object,

- irregular - where the grid discretization is characterized by a low level of uniformity and compacted only locally.

In the space of three-dimensional FEM modeling process, the following types of finite elements are used:

1) One dimensional (Fig. 1) which are in onedimensional space, and generally are not used to simulate engineering processes.

2) Two-dimensional - used to describe twodimensional plane for analysis of stress and deformation. The use of linear equations forces the recording linear changing values of displacements, strains and stresses in the entire area of the element. This process affects the accuracy of the calculation. Therefore, in simulation of metal forming process uses a quadratic function. They have an additional node in the middle of the length of each of its edges. Such elements have a square variable displacement and deformation and stress variables linearly. The elements are classified as two-dimensional triangular elements and quadrangular - see Figure 2.

3) Three-dimensional - called solid faces are used in the analysis of spatial models. These elements have three degrees of freedom at each node. To the kind of three-dimensional elements are classified as tetrahedral and cuboid elements (Fig. 3).

An important criterion for the allocation of finite element computer analysis processes is the number of nodes describing the finite element. Due to the arrangement of nodes comprises the following finite elements:

- first power - wherein the nodes are located on the corners of the element,

- second power - wherein the nodes are located in the corners, and each corner of the element,

- third power - wherein the nodes are located

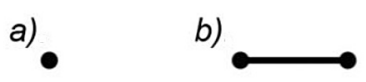

Fig. 1. Examples of one-dimensional finite elements: a) point b) linear

a)
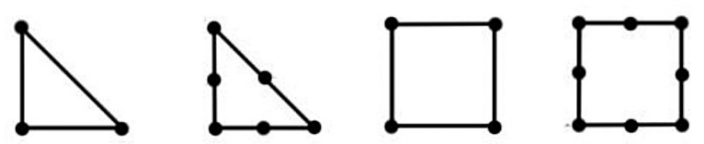

b).

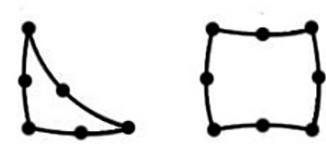

Fig. 2. Examples of finite elements to approximate: a). linear, b). square

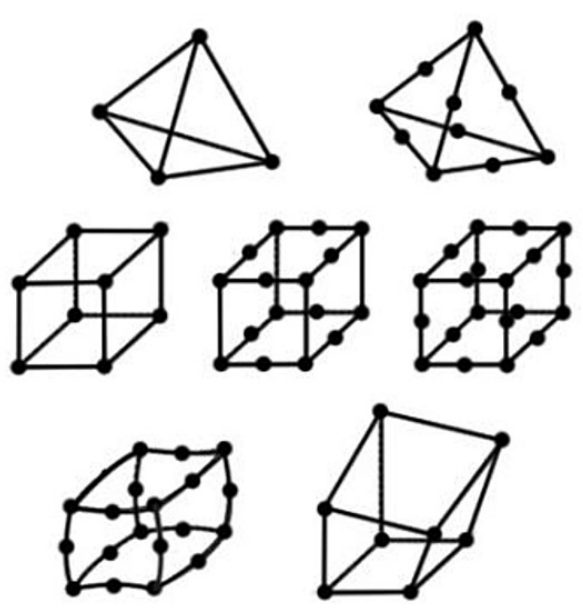

Fig. 3. Examples of finite elements for linear and quadratic approximation

in the corners at the edges of the element and its inside,

- higher powers - where the rank of the element is always equal to the rank of interpolation function or the function shape.

The preprocessor module can set the area of computational definition of tasks and digitization research models. This involves the development of three-dimensional models such technology stereolithography (STL). It is a generalized reflection of the real system. Defining spatial objects concern the determination of the type of cooperation, e.g. a stiff-stiff, plastic or plastic stiffness. The definition of material requires the setting material parameters for example. Young's modulus, Poisson's ratio, the temperature of the phenomenon etc. The elements are interconnected in a finite number of points are edges. The model takes a form of a spatial grid, which is thickened as 
needed. On the basis of equations FEM process is performed to connect the system of equations. The total number of equations in the system is equal to the number of nodes and the number of degrees of freedom of nodes. The behavior of objects in three-dimensional space is defined by giving and receiving degrees of freedom of the individual models and determine the type of traffic. Determination of boundary conditions concern the determination of strength, speed, nature of the contact and friction conditions. To set up the system of equations are introduced boundary conditions. Choosing a solver cannot be entirely dependent on the relative time calculations and hardware but the limitations should take into account the nature and type of material forming process. The choice of solver terms of the type of metal forming process, the plastic described in Table 1.

The usual method of iterative processes shaping plastic materials is Newton-Raphson method. It uses an iterative method of Jakobi matrix, which determines the approximate solution, similar to the actual result. Calculations FEM solver for multicore processors are concurrent through the use of the available number of cores. At present, the FEM uses up to eight cores. Parallel operation allows you to get the results in a much shorter time. Prepared boundary conditions and calculation parameters make it possible to generate a database file and run the calculation process. The analysis results will be available in the postprocessor.
In order to receive reliable results of numerical analysis, it is necessary to choose the function shape. The use of polynomials, which have a higher degree than the third, allows you to get more accurate results, but it is more time-consuming. Reducing the dimensions of the finite element results in increasing the number of nodes searched feature, which also extends the computation time. The solution to this problem is the density of the grid in places where the desired function is changing rapidly and thinning element mesh where the function changes gently.

Under these conditions, the results of displacements are much closer to the exact solution. Another important issue of discretization nodes examined which undergo a plastic deformation is the ability to rebuild remeshing. It involves the re-construction of the grid solver on the basis of the outer contour of the deformed geometry. If the plastic deformation model is very large, its solver sets a new grid with improved geometry to model discrete already deformed and then on the grid requires new calculated values. For each new node new parameters node are calculated as a consequence of at least three nodes removed. This type of process can continue calculations plastic deformation of the material. However, such calculations being averaged over the previous results are not recommended. Each FEM calculation refers to the physical model in question is located in local or major space-coordinate system. This is an area calculation defined by partial differen-

Table 1. The choice of solver processes of plastic forming metal [10]

\begin{tabular}{|c|c|c|c|}
\hline \multirow[b]{2}{*}{ The data model } & \multicolumn{3}{|c|}{ Type solver } \\
\hline & recommended for use & possible to use & $\begin{array}{l}\text { not recommended } \\
\text { for use }\end{array}$ \\
\hline Widespread modeling of objects plastic & CG, DI & NR, SP & \\
\hline Widespread modeling objects plastic elastomers & SP, NR, STD & & DI \\
\hline Matrices of a springy & SP & & CG \\
\hline Dies controlled by force & SP & & CG \\
\hline $\begin{array}{l}\text { Impact on the models of thermal plastic elastomers for } \\
\text { meshing tetragonal }\end{array}$ & SP, NR, MIX & CG, NR & \\
\hline $\begin{array}{l}\text { impact on the models of thermal plastic elastomers for } \\
\text { meshing cubic }\end{array}$ & SP, NR & CG, NR & \\
\hline Objects deformed plastic + plastic (for large deformations) & SP, DI, CC & CG & \\
\hline Objects deformed plastic + plastic (for small deformations) & SP, NR, PEN & DI & \\
\hline Objects deformed elastoplastic & SP, NR, PEN & & DI, CC \\
\hline Models die from stress, models the flexible & SP, NR & CG & \\
\hline Swivel models and symmetrical objects elastoplastic & SP, NR, PEN & & CG, CC \\
\hline Swivel models and symmetrical, artistic objects & SP, DI, CC & CG, NR & \\
\hline $\begin{array}{l}\text { Swivel models and symmetrical objects plastic models of } \\
\text { heat transfer }\end{array}$ & CG & NR & \\
\hline
\end{tabular}


tial equations, and equations for determining the behavior of the so-called the boundary conditions. For most of the analyzed cases, there is a representative of the degree of compaction of the net. It is sufficient to calculate the subject. The research literature $[6,9]$ that the excessive increase of the number of finite elements calculation time increases without affecting the accuracy of the calculations.

The accuracy of the simulation solutions process depends mainly on the accuracy of the approximation of the physical quantities within the component by using the known interpolation functions shape.

With a single shape features basis functions for larger areas of computing are built. FEM solver solution is a linear combination of basic functions. The set of all combinations of basic functions is the set of all possible solutions to the problem analyzed. For this set of basic functions calculations are performed for any point of the space in question. Thanks to continuous model discretization on the mesh model it is possible to achieve results for any node of the study area. In this way they are created in matrices system of linear equations called stiffness matrices. Given that solvers FEM calculate the value of zero is the solution of the matrix of linear functions may be performed at a high speed $[7,8,11]$.

\section{CONCLUSIONS}

The results of the simulation models of plastic deformation processes carried out by the FEM describe the behavior of the system in space approximate and are always subject to some error. There are many causes of error final solution. The final score vitiated by an error of calculation is the algebraic sum of the individual error components.

In numerical analysis there is a relationship between the initial conditions and the geometrical, kinematic and dynamic conditions in the process. These conditions in the implementation of the simulation are referred to as simplified and representative of the their choice based on intuition and knowledge of the investigator. The quality of the results of simulation engineering processes depend on the boundary conditions of the process, the geometry of the study area, the method of discretization, the number and shape of finite elements and physical properties of the object.

\section{REFERENCES}

1. Bathe K.: Finite Element Procedures. PrenticeHall, 1996.

2. Bednarski T.: Mechanika plastycznego płynięcia. PWN, Warszawa 1995.

3. Clough R.W.: Original formulation of the Finite Element Method. Finite Elements in Analysis and Design, 7, 1991.

4. Dębski H., Doświadczalno-numeryczna analiza stanu krytycznego ściskania cienkościennych słupów kompozytowych. Modelowanie matematyczne procesów technicznych, Politechnika Lubelska, 2013, 45-66.

5. Gontarz A., Dziubińska A., Pater Z., Winiarski G., Drozdowski K.: Badania teoretycznodoświadczalne procesu kucia matrycowego stopów magnezu. Mechanik, nr 7-8, 2013.

6. Korga S., Duda A., Kalinowska Ozgowicz E.: The problem discretization objects in the FEM simulation studies. Slovenia 2013.

7. Lacki P.: Simulation of friction in upsetting process. International Journal of Applied Mechanics and Engineering, 2004, 247-255.

8. Lee C.H., Kobayashi S.: New solution to rigidplastic deformation problems using a matrix method. Journal of Engineering for Industry, 95(3), 1973, 865-873.

9. Pater Z., Samołyk G.: Podstawy technologii obróbki plastycznej metali. Politechnika Lubelska, Lublin 2013.

10. Pietrzyk M.: Metody numeryczne w przeróbce plastycznej metali. AGH, Kraków 1992.

11. Zienkiewicz O.C.: Metoda Elementów Skończonych. Arkady, Warszawa 1972. 